\title{
Research on the Ecological Tourism Management based on Community
}

\author{
Junmei Xie \\ Xijing University, Xi'an, 710123, China \\ Email: 1207114370@qq.com
}

\begin{abstract}
With the development of economy, our country's community eco-tourism has entered a period of stable development, the scale of the community ecological tourism market is growing, and the economic value of the community ecological tourism is growing too. Domestic academic circles and business circles have carried on the research and exploration to the management of eco-tourism in different levels. So far in the development of community tourism in China has not formed a more effective, which can obtain a wide range of management methods, and through the development of community ecological tourism can prove that the existing community eco-tourism management model not only hindered the development of community ecological tourism in a certain extent, but also hinder the sustainable use of natural resources in the community environment, therefore, it is necessary to reform the existing community eco-tourism management model, which is the inevitable development of community ecological tourism. In this paper, we analyze the management of community ecological tourism, and put forward some suggestions for reference.
\end{abstract}

Keywords-Community ecological tourism; ecotourism; tourism management; research and analysis

\section{INTRODUCTION}

Eco tourism is a kind of different from the past. It has some special characteristics. The special nature of the community is the people in the community. The community and its residents are the main body of the tourism activities in the ecotourism, and the interests of the community residents are put in the primary position. Makes the residents more active and active participation in the community's environmental construction and resource protection, and realize the sustainable development of Eco tourism environment. As the community ecological tourism has a certain frontier, so far, our country has not a more standard definition of the community ecological tourism. As far as management is concerned, the management of the tourist areas is a sector of the construction sector and related forestry departments, and administrative jurisdiction is a local government, the main personnel are appointed by local government, and the tourism area of the local community and the management agencies and the integration level is not high, resulting in community tourism environment is often ignored, and therefore for the community it is necessary to study and analyze the ecological tourism management.

\section{A SUMMARY OF COMMUNITY ECOLOGICAL TOURISM}

With the booming development of tourism, promoting and promoting the development of community Eco tourism. Eco tourism is not only the common pursuit of the people, but also the requirements of the in line with construction of ecological society which to meet the needs of most people and explore the way of tourism. The generation of community ecological tourism has gained rapid development. After some related research and practice, ecotourism can be understood as a kind of comparatively advanced tourism model, and the high place of this kind of tourism model. It can make a full display of the characteristics of local human nature. Specific performance is in the process of implementing the local folk customs and local characteristics, both coordinate each other, but also to the local residents' participation and external market requirements of the coordination between the two, so that the community in the whole of the tourism activities of the entire tourism. The development characteristic of community ecological tourism is to integrate the concept of community to the tourism industry, which makes the development center of tourism to the community shift, to achieve the community as the center point to spread around, so as to achieve the purpose of tourism. And in the activities of community ecological tourism, it is needed to make full use of the initiative of local residents, to make it become the main body of the development of community tourism, and actively participate in the development model of tourism [1].

\section{THE INFLUENCE FACTORS OF COMMUNITY ECOLOGICAL TOURISM MANAGEMENT}

The tourism industry is developing rapidly, so the scope of its impact is relatively large. In the same time, it will be influenced by many aspects, which can be divided into internal factors and external factors.

Firstly, the main factors that affect the internal influence factors of community ecotourism management are to carry out the local people who carry out the eco tourism activities. These people are usually the residents in the community. So the main management of the community ecological tourism is to control the internal factors of the profit group. In addition to the local profit of the masses and residents, not only includes the tourism companies and government units, the relationship is closely related to the three, in the field of tourism to achieve mutual cooperation, but also produce mutual constraints, which to achieve and promote the development of community eco tourism each other.

Secondly, the external influence factors of the ecological tourism management in the community mainly refers to the non governmental organizations, the general sense of the traveler and the influence of the external environment. The ecological tourism pattern of the 
community can effectively improve the benefit of the community residents in a certain sense, but it can not explain the real needs of the tourists in the time of the standard management. In fact, no matter how the development and reform of tourism industry, the tourism development in the tourism industry has always occupied a dominant position. At the same time, there are a number of non-governmental organizations in the social activities of the tremendous influence to make it very quick to get the recognition and recognition of the community, and the success of the government and the masses in the establishment of an effective communication link. Mainly reflected in the development of some community Eco tourism, some non-governmental organizations can make full use of its internal consultation, coordination, communication and other capabilities, and through their own, recognized and recognized by the community, combined with some of the use of reasonable means to intervene in tourism activities, so as to protect the interests of local residents and fully demonstrate the characteristics and diversity of local ecological culture [2].

Thirdly, the quality of the community is determined by the quality of the main body of the community. The following from the quality of the community to the community ecological tourism management model to discuss the impact. (1) the local government's influence, and the relevant government departments whose functions include environmental protection, construction, forestry, agriculture, religion, etc., these different functions and levels of the relevant government departments, the establishment of the management system, the preparation of personnel and so on are important factors that determine the quality of government. (2) the quality of tourism enterprises, tourism enterprises have many negative effects, is often criticized for short-sighted institutions, reckless with greed, which from the side of the important status of efforts to establish the sustainable development of tourism enterprises in the form of tourism. The development of community ecotourism requires that the tourism enterprises must establish the protection of the local natural human resources and improve the local economic level of the community ecological tourism management model, it is necessary to have a certain sense of responsibility and professional quality of tourism. (3) the quality of community residents, the residents in the community and the local natural history and cultural resources of the most closely related, so that the community residents to participate in the management of community eco-tourism development will play a decisive role. Community residents to participate in the management of community ecological tourism must be required to have a certain cultural knowledge, economic level and the corresponding democratic consciousness, and so on.

\section{THE PROBLEMS IN THE MANAGEMENT OF COMMUNITY ECOLOGICAL TOURISM}

Community ecological tourism is a tourism model which is consistent with the contemporary social groups. However, due to the development of the tourism model is still in its infancy, and the lack of some systematic and scientific management, but also the lack of legal system in this area, which led to a series of problems in the process of running [5].

First, community residents are difficult to play the main role of community eco-tourism model and the traditional model of tourism has obvious differences, mainly reflected in the community eco-tourism will be local residents, while the main problem of the community in the form of an effective set of local residents, the main status of the entire community in the development of ecological tourism, promote and innovation to be fully reflected. The main reason for this trend is that some of our country's community eco-tourism tourism development concept did not make timely changes, leading to those traditional business model is still running and play its role, so that the residents of the core position of the neglect of the core [6]. The lack of main body position is mainly reflected in the passive situation of some residents in the process of community ecological tourism management, but a considerable part of the residents in the process of tourism development, the corresponding degree of participation and decision-making power are slightly less, so that the concept of community eco-tourism has been shifted, which is a serious violation of the initial development of community ecological tourism model. Therefore, in order to strengthen the management of ecological tourism in the community, it is necessary to actively guide the local residents, from all aspects of education and norms, so as to achieve the purpose of enhancing the awareness of the subject [7].

Second, the impact of local culture, the development of local cultural tourism development to the local economic benefits, at the same time it also bring a strong impact, to the tourism destination of the environment and culture .Many times this impact and damage is inevitable, will directly lead to the local cultural characteristics of the situation, thus to the cultural diversity of the 201406 months (on) brand marketing development has caused great obstacles to the development of. Therefore, the development of community tourism should be coordinated with the development and protection of the two, achieve economic growth and cultural construction coordination. However, due to some of the management level and economic benefits of the role, a lot of local cultural characteristics in the process of eco tourism development are gradually missing. For example, a region in the development of the people's life is to maintain the traditional production and lifestyle, and when the community eco-tourism in the local development and development, local residents will be driven by economic interests in the tourism activities, so as to organize tourism and business activities. Although residents are actively involved in the construction of community ecological tourism is the inevitable requirement of the development of eco-tourism, but due to the impact of foreign culture and customs of the local culture and customs began to disappear slowly [8].

Third, the tourism enterprise's management is not good for the development of our country's tourism industry has been facing the problem that the tourism enterprise's management level is not high, this management level is not high content is various, but has the important influence to the tourism development. (1) the low price competition of tourism enterprises has caused the decline of the service 
quality of the whole tourism industry. This is the most obvious problem in China's tourism market now, resulting from mainly by the national consumer pro and market competition intensifies, making the majority of travel agencies began to carry out different levels of low-cost competition, such behavior is not only difficult to protect the tourism industry itself, but also difficult to improve the quality of service [9]. (2) lack of innovation of tourism products in tourism enterprises. This lack of innovation is mainly reflected in the tourism projects and the form of a more single aspect. The highlight of the community ecological tourism is the participation of residents and tourists, but due to the impact of the fixed schedule of tourism enterprises, making the community eco-tourism into a traditional light form of tourism, which has lost its original value and significance, contrary to the sustainable development of community ecological tourism [10].

\section{IMPROVE THE COMMUNITY ECOLOGICAL TOURISM MANAGEMENT MEASURES}

Fist, to guide the community residents to participate in community oriented ecotourism management work of community residents in the community ecological tourism is in the dominant position, has the right to participate in the community tourism management work and related rights and obligations. In order to effectively protect the residents of the community, can make the tourism development direction, positive to listen to the views of residents. Residents for tourism development views and corresponding requirements, at the same time, they will be required for comprehensive consideration. In addition, we can establish a communication platform between each other, you can use these platforms to announce and inform the residents of some of the more important thing or system, and some of the contradictions and problems of the residents appear to be resolved through the establishment of a sound coordination processing department, to achieve real-time understanding of the people, to solve the problem [11].

Second, to construct a scientific and reasonable distribution of interests, to ensure the healthy and smooth development of community ecological tourism, it must be attached great importance to the establishment of its improvement, scientific distribution and compensation mechanism, and the local government should try to protect the interests of residents, and actively encourage residents to engage in related production and management, and encourage residents to obtain good economic benefits through their own labor. In addition, the government can work with some of the relevant enterprises to provide credit services to some residents, so that residents can benefit loans to develop the corresponding tourism projects, however, this involves the development process of technical problems, so it is important to promote the residents to improve their knowledge and cultural quality is also very important [12].

Third, to strengthen the tourism awareness of the community residents in some of the development of ecotourism, usually the elderly will be more, the majority of young adults generally work in the field, so the residents in the community in their own cultural knowledge is generally not high, the lack of knowledge of the relevant tourism. In view of this problem, the government and related departments should carry out active cooperation to the residents of the tourism knowledge training, prompting residents to travel to a more comprehensive understanding. Also on the residents of the relevant ecological environmental awareness to pay attention to, and actively training, after making some tourists came to a house, the local residents can explain in detail for tourists.

\section{CONCLUSION}

To sum up, there are some problems in the management of community eco tourism in our country. For these problems, we must strengthen the practice research, try hard to explore, the main need to do is work of community residents, and to carry out effective education and training work, so that the formation of tourism awareness, so as to promote the development of community ecological tourism.

\section{A. Figures and Tables}

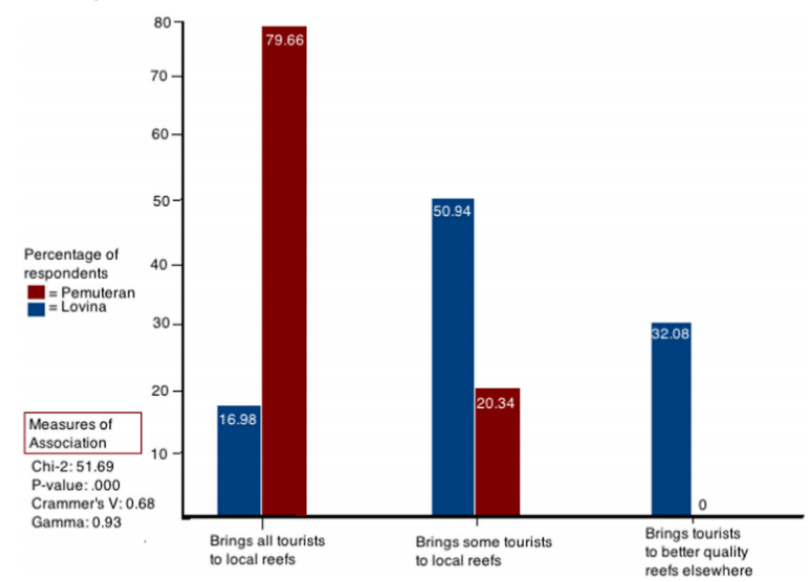

Figure 1. Perceptions of stakeholders: "do you bring your tourists to the village reef or a reef nearby instead?" 
TABLE I STAKEHOLDER PERCEPTIONS ON ECOSYSTEM HEALTH

\begin{tabular}{|c|c|c|c|}
\hline $\begin{array}{c}\text { Survey } \\
\text { Question }\end{array}$ & Variable name & Pemuteran & Lovina \\
\hline $\begin{array}{c}\text { Are the reefs } \\
\text { healthy? }\end{array}$ & Enviro_percep & $92.45 \%$ Yes & $28.81 \%$ Yes \\
& & $\begin{array}{c}7.55 \% \text { No or I don't } \\
\text { know }\end{array}$ & $\begin{array}{c}71.19 \% \text { No or I } \\
\text { don't know }\end{array}$ \\
\hline
\end{tabular}
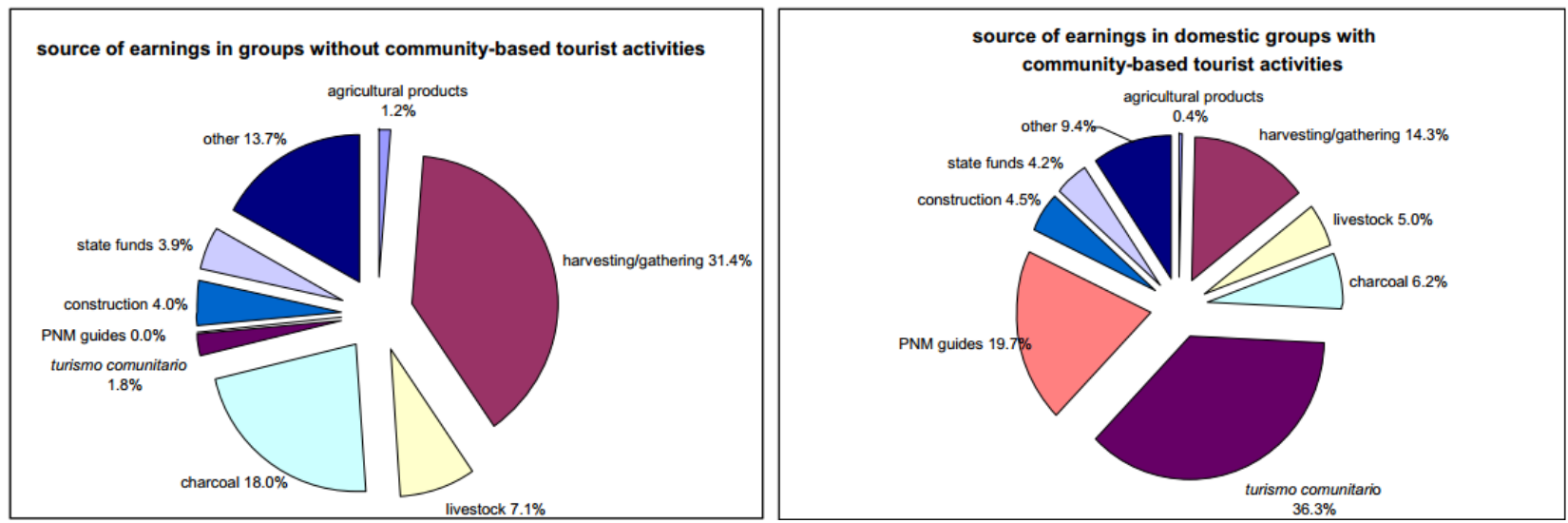

Figure 2. Survey of resources and economic activities

\section{REFERENCES}

[1] Wang Lili. The analysis of ecological tourism management research overview of community tourism based on $[\mathrm{J}]$. (the second half In April), 2012,10.

[2] forest, Huang Zhenfang, Duan Zhongxian, Wang Kun. China tourism development and ecological environment coupling Study [J]. economic geography, 2013,12.

[3] Mao Changyi, Zhang Shulin, Tian Wan Qing town area. Based on the symbiosis (Village) tourism driving mode exploration Please in Chongqing 16 national historical and cultural town as an example [J]. Journal of Chongqing Normal University (NATURAL SCIENCE Learning Edition), 2012,05.

[4] Zang Chuanqin under the protection of the ecological environment of tourism ecology. The research and application of $[\mathrm{J}]$. technology.Interest, 2013,20.

[5] silver, Li Xiaoqin. Mountain tourism influencing factors and empirical research on tropical planning [J].Li Li, 2012,6.
[6] Tang Chengcai, Zhong Linsheng, Cheng Shengkui. Tourism sustainable development of Geographic Science [J].Progress, 2013,06 .

[7] Zhang Hong, the demand model and Empirical Study of the natural tourist attractions in $[\mathrm{J}]$., Guizhou University of Finance and EconomicsNewspaper, 2012,05.

[8] [8] Chen Xiaoying, Lu Xiaobo. The management model of Ecotourism Based on the ecological credit management system

[9] Research [J]. Journal of Beijing International Studies University, 2011,03 .

[10] Zhao Meng. Research progress on the development of ecological tourism in Sichuan forest exploration design, 2010,02.

[11] Xu Jinhua, Chengdu,, Sichuan, forestry science and technology, $2010,06$.

[12] [11] Mophy, Li Jinglong, Jia Shanshan. Tourist scenic spots in China's three power system [J]. ChizhouCollege Journal, 2011,03. 